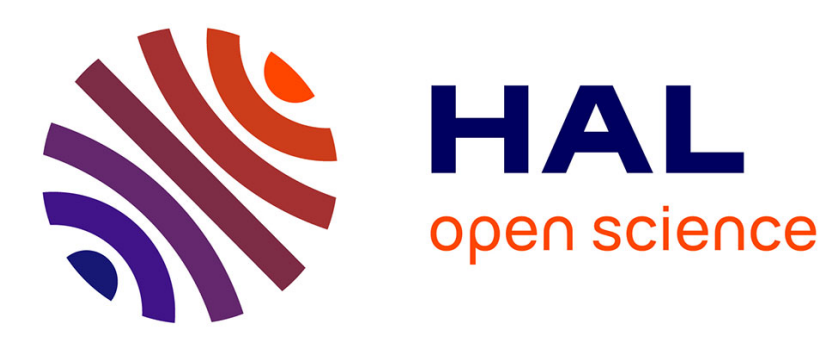

\title{
The new ternary silicide Gd5CoSi2: Structural, magnetic and magnetocaloric properties
}

Charlotte Mayer, Etienne Gaudin, Stéphane Gorsse, Bernard Chevalier

\section{To cite this version:}

Charlotte Mayer, Etienne Gaudin, Stéphane Gorsse, Bernard Chevalier. The new ternary silicide Gd5CoSi2: Structural, magnetic and magnetocaloric properties. Journal of Solid State Chemistry, 2011, 184 (2), pp.325-330. 10.1016/j.jssc.2010.11.023 . hal-00565319

\section{HAL Id: hal-00565319 \\ https://hal.science/hal-00565319}

Submitted on 11 Feb 2011

HAL is a multi-disciplinary open access archive for the deposit and dissemination of scientific research documents, whether they are published or not. The documents may come from teaching and research institutions in France or abroad, or from public or private research centers.
L'archive ouverte pluridisciplinaire HAL, est destinée au dépôt et à la diffusion de documents scientifiques de niveau recherche, publiés ou non, émanant des établissements d'enseignement et de recherche français ou étrangers, des laboratoires publics ou privés. 


\title{
The new ternary silicide $\mathrm{Gd}_{5} \mathrm{CoSi}_{2}$ : structural, magnetic and magnetocaloric properties
}

\author{
Mayer C., Gaudin E., Gorsse S., Chevalier B.
}

Abtract : $\mathrm{Gd}_{5} \mathrm{CoSi}_{2}$ was prepared by annealing at $1003 \mathrm{~K}$. Its investigation by the X-ray powder diffraction shows that the ternary silicide crystallizes in a tetragonal structure deriving from the $\mathrm{Cr}_{5} \mathrm{~B}_{3}$-type (I4/mcm space group; a=7.5799(4) and $c=13.5091(12) \AA$ as unit cell parameters). The Rietveld refinement shows a mixed occupancy on the (8h) site between $\mathrm{Si}$ and $\mathrm{Co}$ atoms. Magnetization and specific heat measurements performed on $\mathrm{Gd}_{5} \mathrm{CoSi}_{2}$ reveal a ferromagnetic behaviour below $T_{C}=168 \mathrm{~K}$. This magnetic ordering is associated to an interesting magnetocaloric effect; the adiabatic temperature change $\Delta T_{a d}$ is about 3.1 and $5.9 \mathrm{~K}$, respectively, for a magnetic field change of 2 and $4.6 \mathrm{~T}$.

\section{Introduction :}

Since the discovery of interesting magnetocaloric effect (MCE) around the room temperature, for the gadolinium [1] and giant MCE in the pseudo-binary compound $\mathrm{Gd}_{5} \mathrm{Si}_{2} \mathrm{Ge}_{2}$ [2], research of new ferromagnetic compounds exhibiting such huge effect has exploded. Indeed, an MCE can be used in the magnetic refrigeration as a potential alternative for conventional gas-compression/expansions refrigeration technology. It was shown that when the ferromagnetic ordering is coupled to a first-order structural transition as for $\mathrm{Gd}_{5} \mathrm{Si}_{2} \mathrm{Ge}_{2}$, the large MCE is usually accompanied with important magnetic and thermal hysteresis, which induces a low working efficiency for applications in magnetic refrigeration [2], [3] and [4]. In this view, as it is rather difficult to introduce and control structural transformations in materials, it is of great interest to optimize an MCE due to the magnetic transition only. In general, large MCE is associated with the use of elements that have a high magnetic moment per atom like rare earths (RE) and some $3 d$ transition metals (Fe, Co). Considering these arguments, we have recently started the investigation of the RE-Co-Si ternary systems and discovered the intermetallics $R E_{6} \mathrm{Co}_{1.67} \mathrm{Si}_{3}$ with $R E=\mathrm{La}, \mathrm{Ce}, \mathrm{Nd}, \mathrm{Gd}$, Tb and Dy [5], [6], [7], [8] and [9]. These ternary silicides crystallize in an hexagonal structure [7] deriving from that of the binary compound $\mathrm{Gd}_{6} \mathrm{Co}_{4.85}$ [10] and no solid solution between these two last intermetallics was evidenced. The $R E_{6} C_{1.67} \mathrm{Si}_{3}$ compounds exhibit interesting magnetic properties: (i) $\mathrm{Gd}_{6} \mathrm{Co}_{1.67} \mathrm{Si}_{3}$ orders ferromagnetically at $294 \mathrm{~K}$, a Curie temperature comparable to that observed for pure gadolinium and exhibits a reversible second-order magnetic transition inducing a remarkable MCE [6], [11], [12] and [13] and (ii) two successive ferro(ferri)magnetic transitions appear below $T_{C}=84$ and $186 \mathrm{~K}^{\text {for }} \mathrm{Nd}_{6} \mathrm{Co}_{1.67} \mathrm{Si}_{3}$ and $\mathrm{Tb}_{6} \mathrm{Co}_{1.67} \mathrm{Si}_{3}$, respectively [8], [9], [11], [14], [15], [16] and [17]. Moreover during the determination of the magnetic structures of these last ternary silicides using neutron powder diffraction [8], we have reported for the first time on the existence of the $R E_{5} \mathrm{CoSi}_{2}(R E=\mathrm{Nd}$ and $\mathrm{Tb})$ compounds, revealed as impurities by this study. Following this work, we carried on the investigation in the Gd-Co-Si system and synthesized the new ternary silicide $\mathrm{Gd}_{5} \mathrm{CoSi}_{2}$. Its existence was not evidenced in the most recent paper devoted to the equilibrium phase diagram at $773 \mathrm{~K}$ in the $\mathrm{Gd}-\mathrm{Co}-\mathrm{Si}$ system [18].

In this paper, we present and discuss the crystallographic, magnetic, thermal and magnetocaloric properties of $\mathrm{Gd}_{5} \mathrm{CoSi}_{2}$. They are compared to that of other ternary and binary compounds existing in the ternary Gd-Co-Si system.

\section{Experimental}

Polycrystalline $\mathrm{Gd}_{5} \mathrm{CoSi}_{2}$ ingots were prepared by arc-melting precisely weighted stoichiometric mixture of high purity elements Gd, Co (99.9\%) and Si (99.9999\%) in a purified argon atmosphere. Melting was performed several times to ensure a good homogeneity. The weight loss during this process was less than 0.2 wt\%. Annealing was finally performed at $1003 \mathrm{~K}$ for 1 month on the sample enclosed in evacuated quartz tubes. No reaction between the sample and the quartz tube was observed.

Both the composition and homogeneity of the annealed sample were checked by microprobe analysis using Cameca SX-100 instrument. The analysis was performed on the basis of intensity measurements of Gd-L $\alpha_{1}, \mathrm{Co}-\mathrm{K} \alpha_{1}$ and Si-K $\alpha_{1}$ X-rays emission lines, which were compared with those obtained for high purity elements $\mathrm{Gd}$, Co and Si used as reference compounds. 
X-ray powder diffraction was performed with the use of a Philips 1050-diffractometer (Cu-Ka radiation) for the phase identification of the as-cast and annealed samples. X-ray powder diffraction data for the characterization of the structural properties of the $\mathrm{Gd}_{5} \mathrm{CoSi}_{2}$ annealed sample were collected with a Philips X-Pert diffractometer operating at room temperature and using $\mathrm{Cu}-\mathrm{K} \alpha_{1}$ radiation $(\lambda=1.54051 \AA)$. The powder diffraction pattern was scanned over the angular range $7.512-119.992^{\circ}$ with a step size of $\Delta(2 \theta)=0.008^{\circ}$. Rietveld refinement was performed using the Jana2006 program package [19]. The background was estimated by a Legendre function with 12 parameters, and the peak shapes were described by a Lorentzian function for $\mathrm{Gd}_{5} \mathrm{CoSi}_{2}$. A correction for roughness (Bragg-Brentano geometry) and absorption correction were introduced to avoid negative value of the atomic displacement parameters (ADPs) induced by the high absorption coefficient of the sample.

Magnetization measurements were performed using a superconducting quantum interference device (SQUID) magnetometer (Quantum Design MPMS-XL) in the temperature range 5-320 K and applied fields up to $4.6 \mathrm{~T}$. Heat capacity was determined with a standard relaxation method with a QD PPMS device. Samples of approximately $40 \mathrm{mg}$ were glued to the sample holder using Apiezon N-grease. The heat capacity of the sample holder and grease was measured just before the sample was studied.

\section{Results and discussion}

\subsection{Synthesis and structural properties}

The analysis of the as-cast sample by X-ray powder diffraction is presented in Fig. 1 and reveals the presence of three phases: the binaries $\mathrm{Gd}_{5} \mathrm{Si}_{3}$ [20] and $\mathrm{Gd}_{3} \mathrm{Co}$ [21] compounds and the $\mathrm{Gd}_{6} \mathrm{Co}_{1.67} \mathrm{Si}_{3}$ ternary silicide [5]. On the contrary, after annealing at $1003 \mathrm{~K}$ (temperature determined after several experiments in accordance with melting temperatures of the phases existing in an as-cast sample) for one month, the $\mathrm{Gd}_{3} \mathrm{Co}$ phase has totally disappeared and the new ternary $\mathrm{Gd}_{5} \mathrm{CoSi}_{2}$ silicide has formed. Some amounts of $\mathrm{Gd}_{5} \mathrm{Si}_{3}$ and $\mathrm{Gd}_{6} \mathrm{Co}_{1.67} \mathrm{Si}_{3}$ also remain as impurities (Fig. 1).

The back-scattered electrons image (microprobe analysis) presented in Fig. 2 confirms the presence of a main phase with $63.8(7) \%$ of $\mathrm{Gd}, 11.5(2) \%$ of $\mathrm{Co}$ and $24.7(4) \%$ of $\mathrm{Si}$ as experimental atomic percentages, close to those expected for the exact $\mathrm{Gd}_{5} \mathrm{CoSi}_{2}$ stoichiometry $\left(62.5 \%\right.$ of $\mathrm{Gd}, 12.5 \%$ of $\mathrm{Co}$ and $25 \%$ of $\mathrm{Si}$ ) and some traces of $\mathrm{Gd}_{6} \mathrm{Co}_{1.67} \mathrm{Si}_{3}$ and $\mathrm{Gd}_{5} \mathrm{Si}_{3}$ impurities. Moreover the boundaries between the $\mathrm{Gd}_{5} \mathrm{Si}_{3}$ and $\mathrm{Gd}_{5} \mathrm{CoSi}_{2}$ domains visible on this image are strictly defined, thus excluding the existence of a solid solution between these two compounds. In other words, the solid solution $\mathrm{Gd}_{5}\left(\mathrm{Si}_{1-x} \mathrm{Co}_{x}\right)_{3}$ does not exist; $\mathrm{Gd}_{5} \mathrm{Si}_{3}$ and $\mathrm{Gd}_{5} \mathrm{CoSi}_{2}$ are in equilibrium at $1003 \mathrm{~K}$.

Analysis of the X-ray powder diffraction pattern (Fig. 3) of the annealed sample shows that the ternary silicide $\mathrm{Gd}_{5} \mathrm{CoSi}_{2}$ crystallizes in the tetragonal $\mathrm{Cr}_{5} \mathrm{~B}_{3}$-type structure (space group $14 / \mathrm{mcm}$ ) with the refined unit cell parameters $a=7.5799(4)$ and $c=13.5091(12) \AA$. The impurity phases $\mathrm{Gd}_{5} \mathrm{Si}_{3}$ [20] and $\mathrm{Gd}_{6} \mathrm{Co}_{1.67} \mathrm{Si}_{3}$ [5] were taken into account with a determined amount equal to 1.2 and $2.7 \mathrm{wt} \%$, respectively. A first model with only silicon atoms in the $4 a$ and $8 \mathrm{~h}$ sites was used and led to the Debye-Waller factors $U_{\text {iso }}=0.038(14) \AA^{2}$ for the $4 a$ site and 0.001(6) $\AA^{2}$ for the $8 h$ site. Mixing of cobalt on both sites was also tested and the sum of their occupancy factors was constrained to be in agreement with the overall composition. A decrease of the occupancy factor of cobalt down to 0 was observed for the $4 a$ site concomitantly to an increase up to $50 \%$ in the $8 \mathrm{~h}$ site. The filling of the $4 a$ site only by cobalt atoms was also tested and the $U_{\text {iso }}$ parameter of cobalt exceeded the value of $0.2 \AA^{2}$. All these attempts proved undoubtedly that the cobalt atoms are localized on the $8 \mathrm{~h}$ site. The occupancy ratio of $\mathrm{Co}$ and $\mathrm{Si}$ on this last position was fixed to 0.5 to fulfill the composition and the ADPs of the lighter elements, $\mathrm{Co}$ and $\mathrm{Si}$, were constrained to be equal to avoid high correlations in the refinement. The final refinement of the atomic positions with isotropic ADPs led to the profile factors $R_{p} / R_{w p}=2.70 / 3.63 \%$ and the reliability factors $R_{F(o b s)} / R_{B(o b s)}=5.56 / 10.47 \%$. The profile refinement is displayed in Fig. 3; the atomic positions with isotropic ADPs are gathered in Table 1 and the interatomic distances in Table 2.

In the tetragonal $\mathrm{Cr}_{5} \mathrm{~B}_{3}$-type structure, boron atoms are located on the two $8 \mathrm{~h}$ and $4 a$ Wyckoff positions. In $\mathrm{Gd}_{5} \mathrm{CoSi}_{2}, \mathrm{a}$ statistical distribution of $\mathrm{Co}$ and $\mathrm{Si} 1$ atoms on the $8 \mathrm{~h}$ Wyckoff position is observed, the $4 a$ position being only filled by $\mathrm{Si} 2$ atoms (Fig. 4). This structure can be described as reported previously for $\mathrm{Nd}_{5} \mathrm{Si}_{3}$ [22] by the alternate stacking of two different slabs along the $c$-axis: the first one $\left(\mathrm{Gd}_{3} \mathrm{CoSi}\right)$ of $\mathrm{U}_{3} \mathrm{Si}_{2}$-type consists of tetragonal $\left[\mathrm{Gd} 2_{8}\right]$ prisms filled with $\mathrm{Gd} 1$ atoms, and pairs of face-sharing trigonal $\left[\mathrm{Gd}_{6}\right]$ prisms filled with the Co/Si1 mixture, and the second one (GdSi) 
consists of tetragonal $\left[\mathrm{Gd}_{8}\right]$ antiprisms filled with Si2 atoms, and pairs of edge-sharing empty $\left[\mathrm{Gd} 2_{4}\right]$ tetrahedra. Similar structure was reported for the compounds $\mathrm{La}_{5} \mathrm{Co}_{0.3} \mathrm{Si}_{2.7}$ and $\mathrm{Nd}_{5} \mathrm{Co}_{0.31} \mathrm{Si}_{2.69}$ [23].

In the sequence $\mathrm{Gd}_{5} \mathrm{Si}_{3} \rightarrow \mathrm{Gd}_{5} \mathrm{CoSi}_{2}$, we observe a change of structure from $\mathrm{Mn}_{5} \mathrm{Si}_{3}$-type $\left(\mathrm{Gd}_{5} \mathrm{Si}_{3}\right)$ to $\mathrm{Cr}_{5} \mathrm{~B}_{3}$-type $\left(\mathrm{Gd}_{5} \mathrm{CoSi}_{2}\right)$. As in this case, a stabilization of the $\mathrm{Cr}_{5} \mathrm{~B}_{3}$-type structure was observed in the past for $\mathrm{Gd}_{5} \mathrm{Co}_{1.73} \mathrm{Bi}$ [24], $\mathrm{Gd}_{5} \mathrm{Ni}_{2} \mathrm{Bi}, \mathrm{Gd}_{5} \mathrm{Pd}_{2} \mathrm{Bi}$ [25] and $\mathrm{Gd}_{5} \mathrm{Au}_{2} \mathrm{Bi}$ [26] through the substitution of $\mathrm{Bi}$ by a transition element in $\mathrm{Gd}_{5} \mathrm{Bi}_{3}$, which crystallize with the $\mathrm{Mn}_{5} \mathrm{Si}_{3}$-type structure [27]. In all these compounds, the smaller atoms (Co, $\mathrm{Ni}, \mathrm{Pd}, \mathrm{Au}$ ) occupy preferentially the $8 \mathrm{~h}$ site, whereas the bigger $\mathrm{Bi}$ atoms are located on the $4 \mathrm{a}$ site. Similar remark can be made for $\mathrm{Gd}_{5} \mathrm{CoSi}_{2}$ since the smaller Co atoms (the metallic radius $r$ give $r_{C_{0}}=1.252 \AA<r_{S i}=1.319 \AA$ [28]) occupy partially the $8 \mathrm{~h}$ site.

In $\mathrm{Gd}_{5} \mathrm{CoSi}_{2}$, the mixture $\mathrm{Co} / \mathrm{Si1}$ (8h site) is located in trigonal $\left[\mathrm{Gd}_{6}\right.$ ] prisms as observed for $\mathrm{Si}$ atoms in $\mathrm{Gd}_{5} \mathrm{Si}_{3}$ [20], and $\mathrm{Si}$ and $\mathrm{Co} 2$ atoms in $\mathrm{Gd}_{6} \mathrm{Co}_{1.67} \mathrm{Si}_{3}$ [5]. The average $\mathrm{Co} / \mathrm{Si1}-\mathrm{Gd} 2$ distance of $2.96 \AA$ determined here for $\mathrm{Gd}_{5} \mathrm{CoSi}_{2}(\mathrm{Table}$ 2 ) is between those of $\mathrm{Si}-\mathrm{Gd}$ reported for $\mathrm{Gd}_{5} \mathrm{Si}_{3}(3.025 \AA)$ and $\mathrm{Gd}_{6} \mathrm{Co}_{1.67} \mathrm{Si}_{3}(3.07 \AA)$ and those of Co2-Gd existing in $\mathrm{Gd}_{6} \mathrm{Co}_{1.67} \mathrm{Si}_{3}(2.932 \AA)$. Also, it is interesting to note that the average distance Co/Si1-Gd2 $(2.960 \AA)$ is smaller than that of Si2-Gd2 (3.163 $\AA$ ) in agreement with the fact that the smaller Co atoms occupy the smaller $8 h$ site. The $\mathrm{Gd}-\mathrm{Gd}$ distances vary from 3.362 to $3.987 \AA$ and most of them are smaller than the sum of metallic radii (3.604 $\AA$ ) (Table 2). This behaviour suggests the existence of strong $\mathrm{Gd}-\mathrm{Gd}$ magnetic interactions in the ternary silicide $\mathrm{Gd}_{5} \mathrm{CoSi}_{2}$.

\subsection{Physical properties}

Fig. 5 shows the temperature dependence of the zero-field cooled (ZFC) and field cooling (FC) magnetization $M$ of $\mathrm{Gd}_{5} \mathrm{CoSi}_{2}$ (annealed sample) measured with an applied field of $0.05 \mathrm{~T}$. These curves display two rather sharp increases in $M$ at the Curie temperatures $T_{C 1}=298 \mathrm{~K}$ and $T_{C 2}=168 \mathrm{~K}$ (temperatures defined as the extrema of the derivative curve $d M / d T$ versus $T)$. The first small increase at $T_{C 1}$ corresponds to the ferromagnetic ordering of the impurity phase $\mathrm{Gd}_{6} \mathrm{Co}_{1.67} \mathrm{Si}_{3}$ [5]. The second increase, at $T_{C 2}=168 \mathrm{~K}$, also indicates the occurrence of a ferromagnetic ordering that can be attributed to the new phase $\mathrm{Gd}_{5} \mathrm{CoSi}_{2}$. Above $320 \mathrm{~K}$, the reciprocal magnetic susceptibility $X_{m}{ }^{-1}$ of $\mathrm{Gd}_{5} \mathrm{CoSi}_{2}$, measured with an applied field of $3 \mathrm{~T}$ (inset of Fig. 5), follows Curie Weiss law. The experimental value of the effective magnetic moment $\mu_{\text {eff }}=7.95 \mu_{\mathrm{B}} / \mathrm{Gd}$ is close to the calculated value for a free $\mathrm{Gd}^{3+}$ ion $\left(7.94 \mu_{\mathrm{B}} / \mathrm{Gd}\right)$. This suggests that Co is nonmagnetic in this ternary silicide.

These magnetization measurements indicate that the partial replacement of an $\mathrm{Si}$ by Co atoms in $\mathrm{Gd}_{5} \mathrm{Si}_{3}$ induces a modification of the magnetic behaviour from antiferromagnetism to ferromagnetism. Indeed, $\mathrm{Gd}_{5} \mathrm{Si}_{3}$ orders antiferromagnetically below $T_{N}=55 \mathrm{~K}$ [29], whereas as determined here $\mathrm{Gd}_{5} \mathrm{CoSi}_{2}$ exhibits a ferromagnetic behaviour below $168 \mathrm{~K}$. Similar remark was claimed previously during the replacement of $\mathrm{Bi}$ by $\mathrm{Ni}$ atoms in $\mathrm{Gd}_{5} \mathrm{Bi}_{3}$; strong antiferromagnetic interactions exist in $\mathrm{Gd}_{5} \mathrm{Bi}_{3}$ [30], but the compound $\mathrm{Gd}_{5} \mathrm{Ni}_{0.71} \mathrm{Bi}_{2.29}$ presents a ferromagnetic ordering below $162 \mathrm{~K}$ [31]; a Curie temperature close to that observed for $\mathrm{Gd}_{5} \mathrm{CoSi}_{2}$.

The temperature dependence of the specific heat $\mathrm{Cp}$ of $\mathrm{Gd} 5 \mathrm{CoSi} 2$ measured in zero magnetic field is shown in Fig. 6.

The $\mathrm{Cp}$ versus T curve exhibits two $\lambda$-type peaks at 295 and $165 \mathrm{~K}$; temperatures defined by the maximum of the peaks. These results are in an excellent agreement with the magnetization data and confirm the presence of a magnetic transition near $168 \mathrm{~K}$ for $\mathrm{Gd}_{5} \mathrm{CoSi}_{2}$. According to the Dulong-Petit law, only the lattice contribution to $\mathrm{Cp}(\mathrm{T})$ is effective at high temperature. The $\mathrm{Cp}$ limit of a compound with $\mathrm{n}$ atoms per unit cell must then be equal to the theoretical value of $3 n R$, with $R=8.31 \mathrm{~J} \mathrm{~mol}^{-1} \mathrm{~K}^{-1}$ the gas constant. For $\mathrm{Gd}_{5} \mathrm{CoSi}_{2}$, this calculated value is equal to $199.4 \mathrm{~J} \mathrm{~mol}^{-1} \mathrm{~K}^{-1}(\mathrm{n}=8)$, which is $13 \%$ less than the measured one of $229.5 \mathrm{~J} \mathrm{~mol}^{-1} \mathrm{~K}^{-1}$ at $312 \mathrm{~K}$. The exceeding value is probably attributable to the magnetic contribution of the impurity $\mathrm{Gd}_{6} \mathrm{Co}_{.67} \mathrm{Si}_{3}$, which presents a Curie temperature around $298 \mathrm{~K}$ [5] and we can assume that the $\mathrm{Gd}_{5} \mathrm{CoSi}_{2}$ ternary silicide brings only its lattice contribution to $\mathrm{Cp}$. As the existence of the nonmagnetic isomorphous compounds $\mathrm{La}_{5} \mathrm{CoSi}_{2}$ and $\mathrm{Y}_{5} \mathrm{CoSi}_{2}$ is not reported in the literature and our attempts to synthesize them were not successful, the only way to estimate the magnetic contribution $\mathrm{Cm}$ is to estimate and subtract both electronic contribution Cel and lattice (phonon) contribution Clat to the measured $\mathrm{Cp}$. Cel is fitted linearly at low temperatures and the Debye function is used to estimate Clat in the full temperature range. The following expression was used to fit the experimental curve apart from $\mathrm{C}_{\mathrm{m}}$ 


$$
C_{e l}(T)+C_{\text {lat }}(T)=\gamma T+9 n R\left(\frac{T}{\theta_{D}}\right)^{3} \int_{0}^{x_{D}} \frac{x^{4} e^{x}}{\left(e^{x}-1\right)^{2}} d x
$$

With $y$ the Sommerfield coefficient, $\theta_{D}$ the Debye temperature and $x_{D}=\theta_{D} / T$. By adjusting the curve, a good fit represented by full line in Fig. 6 can be obtained. It was reached with the following parameters: $y=100 \mathrm{~mJ} \mathrm{~mol}^{-1} \mathrm{~K}^{-2}$ and $\theta_{D}=210 \mathrm{~K}$; this last temperature is coherent with those reported for other $\mathrm{Gd}$ based materials like $\mathrm{GdMg}\left(\theta_{D}=228 \mathrm{~K}\right)$ [32] and $\mathrm{Gd}_{5} \mathrm{Si}_{2} \mathrm{Ge}_{2}\left(\theta_{D}=250 \mathrm{~K}\right)$ [33]. The magnetic contribution $C_{m}$, plotted in the inset of Fig. 6 , was deducted as follows: $C_{m}=C_{p}-\left(C_{e l}+C_{\text {lat }}\right)$. The two peaks at 165 and $295 \mathrm{~K}$ appear clearly on the $C_{m}$ versus $T$ curve. The $C_{m}$ value attributed to the magnetic transition of $\mathrm{Gd}_{5} \mathrm{CoSi}_{2}$ was estimated at $C_{m}{ }^{\text {peak }} \sim 97 \mathrm{~J} \mathrm{~mol}^{-1} \mathrm{~K}^{-1}$ at the edge of the $\lambda$ peak at $165 \mathrm{~K}$. Therefore, with five $\mathrm{Gd}^{3+}$ ions per unit formula of $\mathrm{Gd}_{5} \mathrm{CoSi}_{2}$, the value corresponding to each one is $C_{m}\left(\mathrm{Gd}^{3+}\right) \sim 19.4 \mathrm{~J}$ $\left(\mathrm{Gd}^{3+}\right) \mathrm{mol}^{-1} \mathrm{~K}^{-1}$. This value is in good agreement with that of $20.15 \mathrm{~J}\left(\mathrm{Gd}^{3+}\right) \mathrm{mol}^{-1} \mathrm{~K}^{-1}$ predicted by Blanco et al. [34] for simple ferromagnetic structure using a mean-field model.

The evolution of the magnetic entropy $S_{m}$ versus $T$ can then be calculated with the equation:

$$
S_{m}(T)=\int_{0}^{T} \frac{C_{m}(T)}{T} d T
$$

The temperature dependence of $S_{m}$, presented in Fig. 7, shows a pronounced increase of $S_{m}$ after the ferromagnetic ordering temperature $\left(T_{C}=165 \mathrm{~K}\right)$ of $\mathrm{Gd}_{5} \mathrm{CoSi}_{2}$. The $S_{m}$ value is $12.2 \mathrm{~J}(\mathrm{Gd}) \mathrm{mol}^{-1} \mathrm{~K}^{-1}$ at $T_{C}$ and $13.9 \mathrm{~J}(\mathrm{Gd}) \mathrm{mol}^{-1} \mathrm{~K}^{-1}$ at $312 \mathrm{~K}$, respectively, $71 \%$ and $80 \%$ of the theoretical value $\mathrm{R} \ln (2 \mathrm{~J}+1)=17.3 \mathrm{~J}(\mathrm{Gd}) \mathrm{mol}^{-1} \mathrm{~K}^{-1}$ for one mole of $\mathrm{Gd}^{3+}$ $(J=7 / 2)$. It indicates some persistent magnetic interaction after $T_{C}$, which is in correlation with the presence of the parasite ferromagnetic phase $\mathrm{Gd}_{6} \mathrm{Co}_{1.67} \mathrm{Si}_{3}$.

Isothermal field dependence of magnetization $M$ measurements were performed with decreasing magnetic field from 4.6 to $0 \mathrm{~T}$ and for various temperatures between 10 and $310 \mathrm{~K}$ (Fig. 8); no remanence was evidenced. At $10 \mathrm{~K}, M$ saturates at $4.6 \mathrm{~T}$ and reaches $6.8 \mu_{\mathrm{B}}$ as magnetic moment per $\mathrm{Gd}^{3+}$, which is slightly smaller than the theoretical value for a free $\mathrm{Gd}^{3+}$ ion, $g_{J} J=7 \mu_{\mathrm{B}}$ ( $g_{\mathrm{J}}$ being the Landé factor and $J$ the total angular momentum). Finally, we must notice that the variation of $M$ versus the applied field tends to linearity only above $310 \mathrm{~K}$ (temperature higher than Curie temperature of the impurity $\mathrm{Gd}_{6} \mathrm{Co}_{1.67} \mathrm{Si}_{3}$ ), as expected.

The isothermal magnetic entropy change $\Delta S_{m}$ was determined from the magnetization data (Fig. 8) by integrating Maxwell relation:

$$
\Delta S_{m}(T, \Delta H)=\int_{H_{0}}^{H_{f}}\left(\frac{\partial M(T, H)}{\partial T}\right)_{H} d H
$$

The results for $\mathrm{Gd}_{5} \mathrm{CoSi}_{2}$, in applied fields of $\Delta H=2$ and 4.6 T, are reported in Fig. 9(a). A rather high peak centered between 165 and $175 \mathrm{~K}$ is observed, i.e. around the Curie temperature of this compound, as expected for the magnetocaloric effect. $\Delta S_{m}$ reaches the maximum value of $-8.7 \mathrm{~J} \mathrm{~K}^{-1} \mathrm{~kg}^{-1}$ at $4.6 \mathrm{~T}$ and $-4.7 \mathrm{~J} \mathrm{~K}^{-1} \mathrm{~kg}^{-1}$ at $2 \mathrm{~T}$.

The adiabatic temperature change $\Delta T_{\text {ad }}$ was determined by combining the heat capacity measurements at zero field (Fig. 6) and the magnetization data (Fig. 8) via the following equation proposed by Foldeaki et al. [35], which neglects the dependence of $C_{p}$ over the applied field $H$ :

$$
\Delta T_{a d}(T)=-\frac{T}{C_{p}(T)_{H=0}} \Delta S_{m}(T)_{\Delta H}
$$


$\Delta T_{\text {ad }}$ versus $T$ for $\mathrm{Gd}_{5} \mathrm{CoSi}_{2}$ is plotted in Fig. $9(\mathrm{~b})$ for $\Delta H=2$ and $4.6 \mathrm{~T}$. As expected, a peak near the Curie temperature of the ternary silicide is observed, with a maximum of $\Delta T_{\text {ad }}$ about 3.1 and $5.9 \mathrm{~K}$ for $\Delta H=2$ and $4.6 \mathrm{~T}$, respectively. The procedure for the indirect calculation of $\Delta T_{a d}$, described as the most accurate by Pecharsky et al. [36], consisting in the use of the heat capacity measurement to calculate the total entropy at constant field gave the same $\Delta T_{a d}$ versus $T$ curve than this one. Indeed, due to the fact that $C_{p}$ was measured at zero magnetic field only, it is impossible to get a more accurate estimation of $\Delta T_{a d}$ whatever the calculation method applied.

The $\Delta S_{m}{ }^{\text {peak }}$ values reported here for $\mathrm{Gd}_{5} \mathrm{CoSi}_{2}$ are compared to that of other magnetocaloric materials existing in the ternary $\mathrm{Gd}-\mathrm{Co}-\mathrm{Si}$ system (Table 3). It appears that this new ternary silicide compares well with $\mathrm{Gd}_{12} \mathrm{Co}_{7}$ of which $T_{C}=163 \mathrm{~K}$ is really close to that of $\mathrm{Gd}_{5} \mathrm{CoSi}_{2}$, and which was the most efficient material with a paramagnetic to ferromagnetic transition in this system so far. Absolute values for pure $\mathrm{Gd}$ are still a little higher, but when expressed per weight amount of $\mathrm{Gd}$, they get really close. Finally, only $\mathrm{Gd}_{3} \mathrm{Co}$, with its metamagnetic transition at $128 \mathrm{~K}$ still has the most elevated $\Delta S_{m}{ }^{\text {peak }}$ values, but at a lower temperature.

\section{Conclusion}

The investigation of the system $\mathrm{Gd}-\mathrm{Co}-\mathrm{Si}$ in the rich part in gadolinium has highlighted a new ternary silicide $\mathrm{Gd}_{5} \mathrm{CoSi}_{2}$. This compound obtained after annealing at $1003 \mathrm{~K}$, adopts a disordered tetragonal structure deriving from the $\mathrm{Cr}_{5} \mathrm{~B}_{3}$ type. This structure is different to that reported for the binary compound $\mathrm{Gd}_{5} \mathrm{Si}_{3}$ (hexagonal, $\mathrm{Mn}_{5} \mathrm{Si}_{3}$-type), which is in equilibrium with $\mathrm{Gd}_{5} \mathrm{CoSi}_{2}$ at $1003 \mathrm{~K}$. The ternary silicide presents ferromagnetic ordering at $168 \mathrm{~K}$ that could be associated to a very interesting magnetocaloric effect of $5.9 \mathrm{~K}$ in a magnetic field change of $4.6 \mathrm{~T}$. This result encourages us to consider in the future other compounds $R E_{5} \mathrm{CoSi}_{2}$, with for instance $R E=\mathrm{Nd}, \mathrm{Tb}$.

\section{Acknowledgments}

The authors are indebted to the Conseil Régional d'Aquitaine for financial support, especially C. M. for a Ph.D. grant.

\section{References}

1 S. Yu, A.M. Dan'kov, V.K. Tishin, Pecharsky and K.A. Gschneidner Jr., Phys. Rev. B 57 (1998), pp. 3478-3490.

2 V.K. Pecharsky and K.A. Gschneidner Jr., Phys. Rev. Lett. 78 (1997), pp. 4494-4497.

3 V.A. Cherchenko, E. Cesari, V.V. Kokorin and I.N. Vitenko, Scr. Metall. Mater. 33 (8) (1995), pp. 1239-1244.

4 G.H. Wen, R.K. Zheng, X.X. Zhang, W.H. Wang, J.L. Chen and G.H. Wu, J. Appl. Phys. 91 (10) (2002), pp. 8537-8539.

5 E. Gaudin, F. Weill and B. Chevalier, Z. Naturforsch. 61b (2006), pp. 825-832.

6 E. Gaudin, S. Tencé, F. Weill, J. Rodriguez-Fernandez and B. Chevalier, Chem. Mater. 20 (2008), pp. $2972-2979$.

7 B. Chevalier, E. Gaudin and F. Weill, J. Alloys Compd. 442 (2007), pp. 149-151.

8 S. Tencé, E. Gaudin, G. André and B. Chevalier, J. Phys. D: Appl. Phys. 42 (2009), p. 165003.

9 E. Gaudin, S. Tencé and B. Chevalier, Solid State Sci. 10 (2008), pp. 481-485.

10 S. Tencé, E. Gaudin and B. Chevalier, Intermetallics 18 (2010), pp. 1216-1221.

11 S.N. Jammalamadaka, N. Mohapatra, S.D. Das, K.K. Iyer and E.V. Sampathkumaran, J. Phys.: Condens. Matter 20 (2008), p. 425204.

12 J. Shen, J.F. Wu and J.R. Sun, J. Appl. Phys. 106 (2009), p. 083902.

13 J. Shen, Y.X. Li, Q.Y. Dong, F. Wang and J.R. Sun, Chin. Phys. B 17 (2008), pp. 2268-2271.

14 N. Mohapatra, S.N. Jammalamadaka, S.D. Das and E.V. Sampathkumaran, Phys. Rev. B 78 (2008), p. 054442.

15 A. Haldar, N.K. Singh, K.G. Suresh and A.K. Nigam, Physica B 405 (2010), pp. 3446-3451.

16 J. Shen, F. Wang, Y.X. Li, J.R. Sun and B.G. Shen, Chin. Phys. 16 (2007), pp. 3853-3857.

17 J. Shen, Y.X. Li and J.R. Sun, J. Alloys Compd. 476 (2009), pp. 693-696.

18 S. Wu, J. Yan, L. Zhang, W. Qin, L. Zeng and Y. Zhuang, Z. Metallkd 91 (2000), pp. 373-374.

19 V. Petricek, M. Dusek and L. Palatinus Jana, Jana 2006. The Crystallographic Computing System Jana, Institute of Physics, Praha, Czech Republic (2006).

20 V. Babizhetskyy, J. Roger, S. Députier, R. Jardin, J. Bauer and R. Guérin, J. Solid State Chem. 177 (2004), pp. $415-424$.

21 O.A.W. Strydom and L. Alberts, J. Less-Common Met. 22 (1970), pp. 511-515.

22 J. Roger, V. Babizhetskyy, R. Jardin, J.-F. Halet and R. Guérin, J. Alloys Compd. 415 (2006), pp. 73-84.

23 D. Gout, E. Benbow and Gordon J. Miller, J. Alloys Compd. 338 (2002), pp. 153-164.

24 A.V. Tkachuk, H. Bie and A. Mar, Intermetallics 16 (2008), pp. 1185-1189.

25 Y. Mozharivskyj and H.F. Franzen, J. Solid State Chem. 152 (2000), pp. 478-485.

26 Yu Verbovytsky and K. Latka, J. Alloys Compd. 438 (2007), pp. L4-L6.

27 D. Hohnke and E. Parthe, J. Less-Common Met. 17 (1969), pp. 291-296.

28 W.B. Pearson, The Crystal Chemistry and Physics of Metals and Alloys, Wiley, New York (1972).

29 F. Canepa, S. Cirafici and M. Napoletano, J. Alloys Compd. 335 (2002), pp. L1-L4.

30 J. Szade and M. Drzyzga, J. Alloys Compd. 299 (2000), pp. 72-78.

31 V. Svitlyk, F. Fei and Y. Mozharivskyj, J. Solid State Chem. 181 (2008), pp. 1080-1086.

32 U. Kobler, R.M. Mueller, W. Schnelle and K. Fischer, J. Magn. Magn. Mater. 188 (1998), pp. 333-345.

33 O. Svitelskiy, A. Suslov, D.L. Schlagel, T.A. Lograsso, K.A. Gschneidner Jr. and V.K. Pecharsky, Phys. Rev. B 74 (2006), p. 184105.

34 J.A. Blanco, D. Gignoux and D. Schmitt, Phys. Rev. B 43 (1990), pp. 13145-13151.

35 M. Foldeaki, R. Chahine, B.R. Gopal, T.K. Bose, X.Y. Liu and J.A. Barclay, J. Appl. Phys. 83 (1998), p. 2727. 
36 V. Pecharsky and K.A. Gschneidner Jr., J. Appl. Phys. 86 (1999), pp. 565-575.

37 X. Chen and Y.H. Zhuang, Solid State Commun. 148 (2008), pp. 322-325.

38 S.K. Tripathy, K.G. Suresh and A.K. Nigam, J. Magn. Magn. Mater. 306 (2006), pp. 24-29.

39 Q. Zhang, B. Li, X.G. Zhao and Z.D. Zhang, J. Appl. Phys. 105 (2009), p. 053902. 

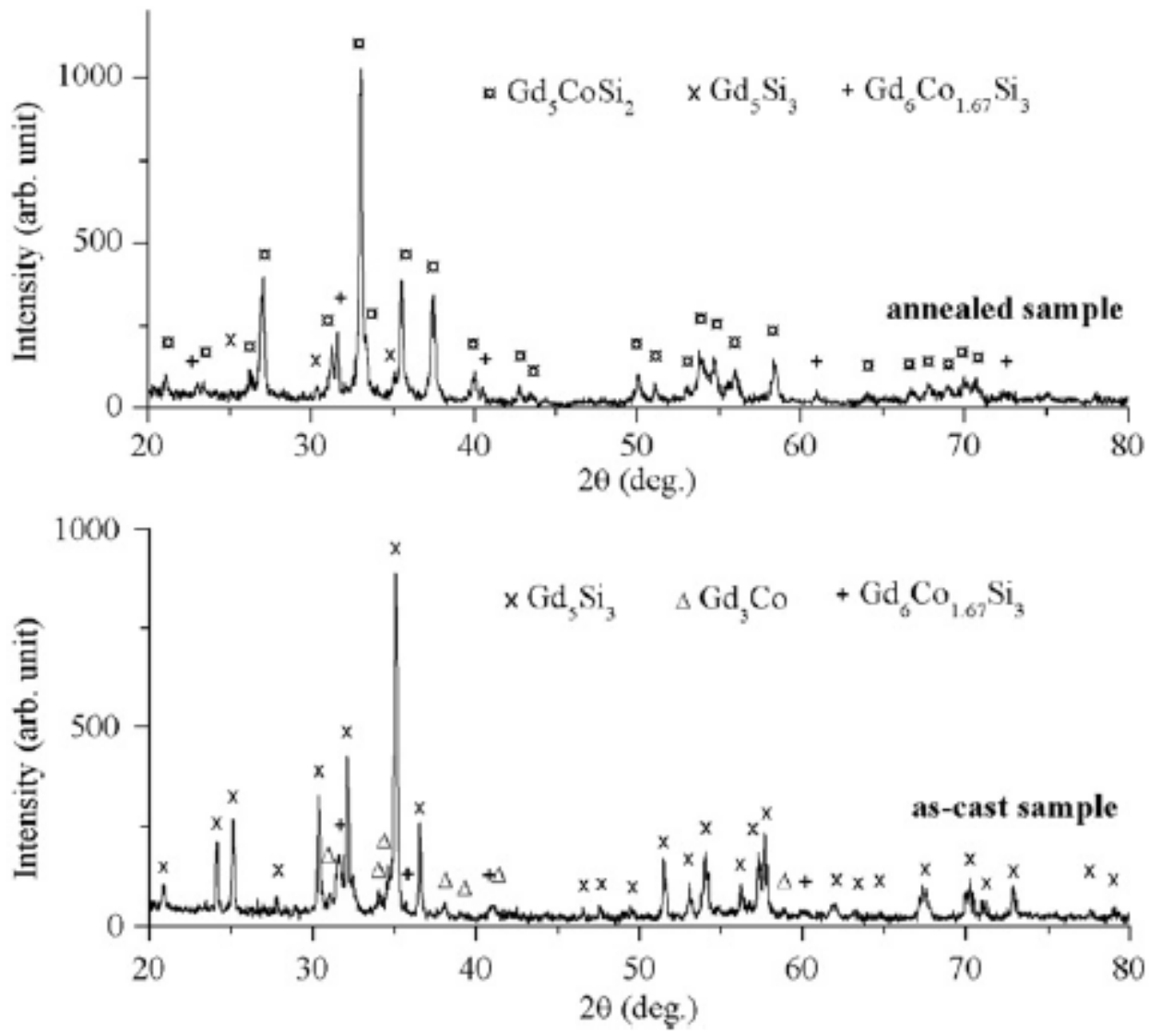

Fig. 1. X-ray powder patterns of $\mathrm{Gd}_{5} \mathrm{CoSi}_{2}$ sample after melting (as-cast) followed by annealing at $1003 \mathrm{~K}$ (annealed). The phases are identified by symbols as indicated on top of the patterns.

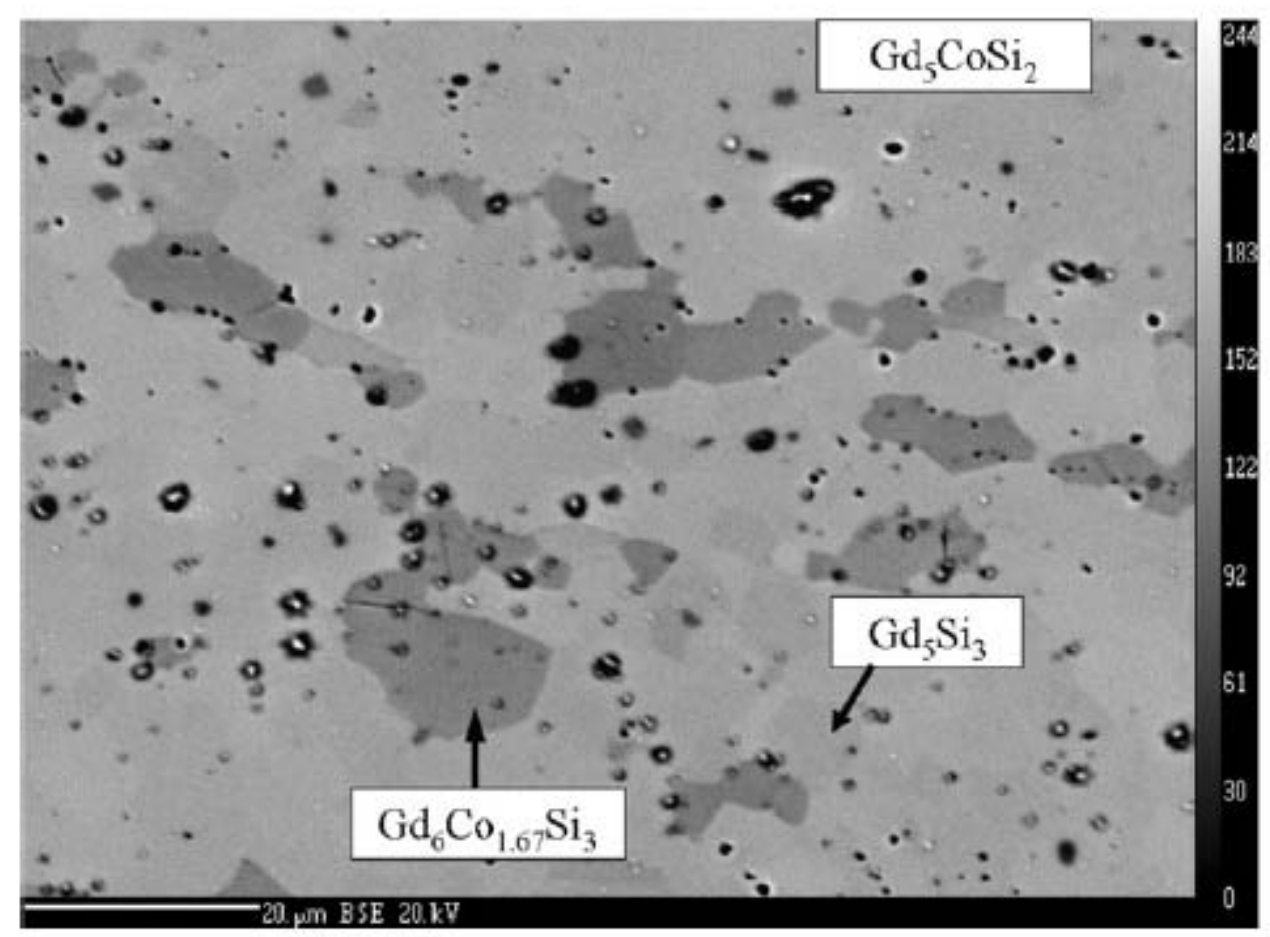

Fig. 2. Microstructure of the annealed sample. The main phase $\mathrm{Gd}_{5} \mathrm{CoSi}_{2}$ and the impurities $\mathrm{Gd}_{5} \mathrm{Si}_{3}$ and $\mathrm{Gd}_{6} \mathrm{Co}_{1.67} \mathrm{Si}_{3}$ are indicated. The black round areas correspond to the opened porosities. 


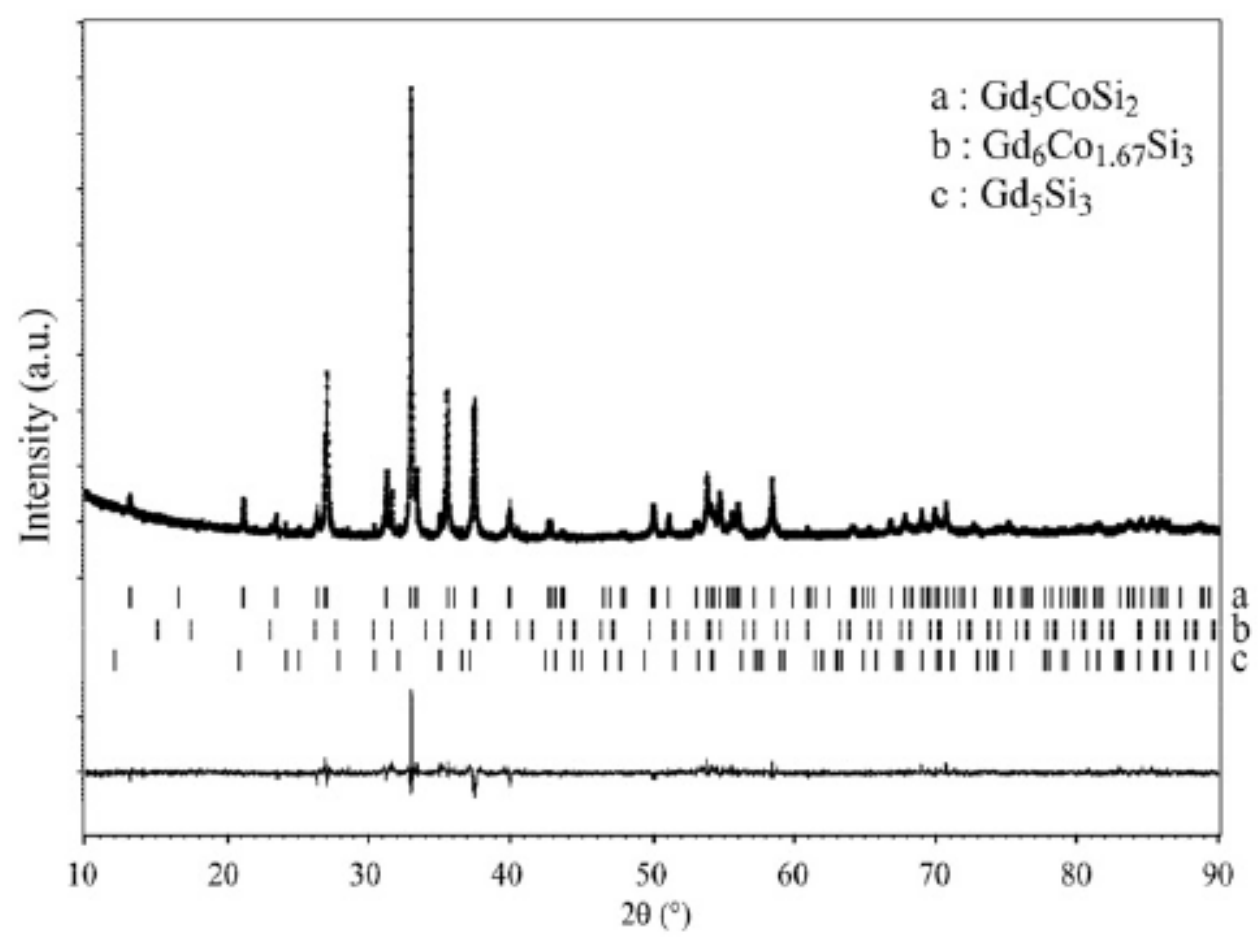

Fig. 3. Rietveld refinement of $\mathrm{Gd}_{5} \mathrm{CoSi}_{2}$ (annealed sample) XRD powder pattern measured with $\mathrm{Cu}-\mathrm{K} \alpha_{1}$ radiation $(\lambda=1.54051 \AA)$ at $T=293 \mathrm{~K}$ (observed (cross), calculated (full line), and difference (bottom) profiles). For the sake of clarity, only the angle range $10-90$ was displayed, no Bragg peaks are observed below $10^{\circ}$. The Bragg peak positions are indicated by tick marks for the $\mathrm{Gd}_{5} \mathrm{CoSi}_{2}(\mathrm{a})$ main phase and the impurities $\mathrm{Gd}_{6} \mathrm{Co}_{1.67} \mathrm{Si}_{3}(\mathrm{~b})$ and $\mathrm{Gd}_{5} \mathrm{Si}_{3}(\mathrm{c})$.
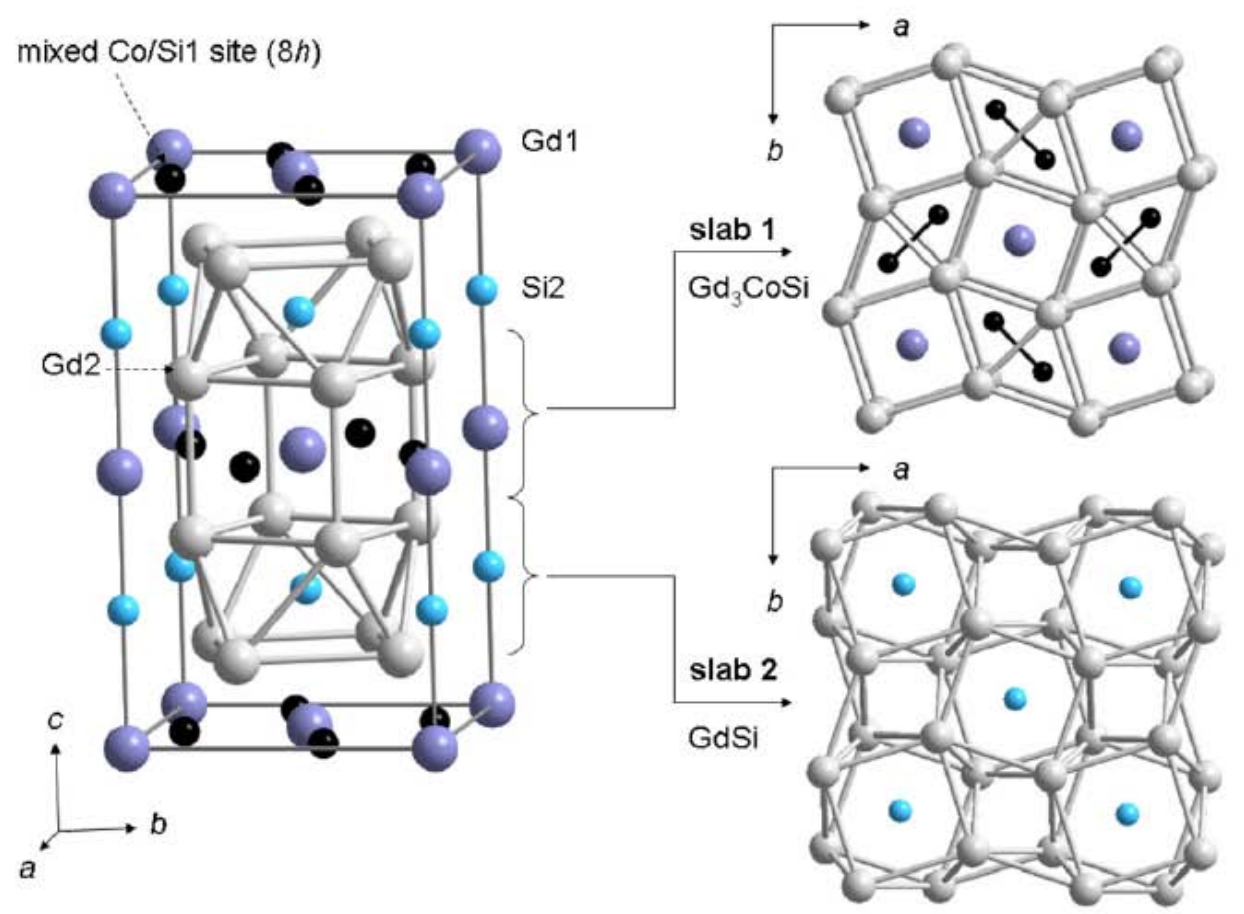

Fig. 4. Structure of $\mathrm{Gd}_{5} \mathrm{CoSi}_{2}$ with the tetragonal $\mathrm{Cr}_{5} \mathrm{~B}_{3}$-type, built as a stacking of two types of slabs along the $c$-axis (the slab 1 corresponds to Gd $\mathrm{C}_{3} \mathrm{CoSi}$ and the slab 2 to $\mathrm{GdSi}$ ). Co atoms fill half of the $8 \mathrm{~h}$ sites located in slab 1 (black circles). 


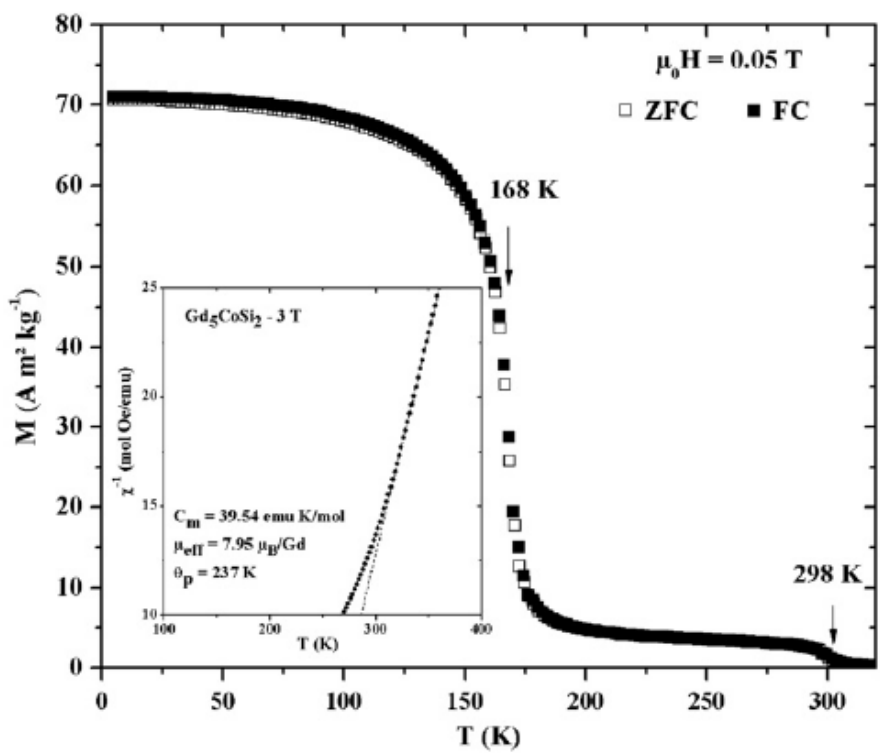

Fig. 5. Temperature dependence of the magnetization $M$ of $\mathrm{Gd}_{5} \mathrm{CoSi}_{2}$ (annealed sample) measured with an applied field of $0.05 \mathrm{~T}$ (open and closed symbols correspond, respectively, to the zero-field cooled (ZFC) and field cooling (FC) processes). The inset displays its reciprocal magnetic susceptibility $\chi_{m}^{-1}$ versus temperature (the dashed line follows Curie Weiss law).

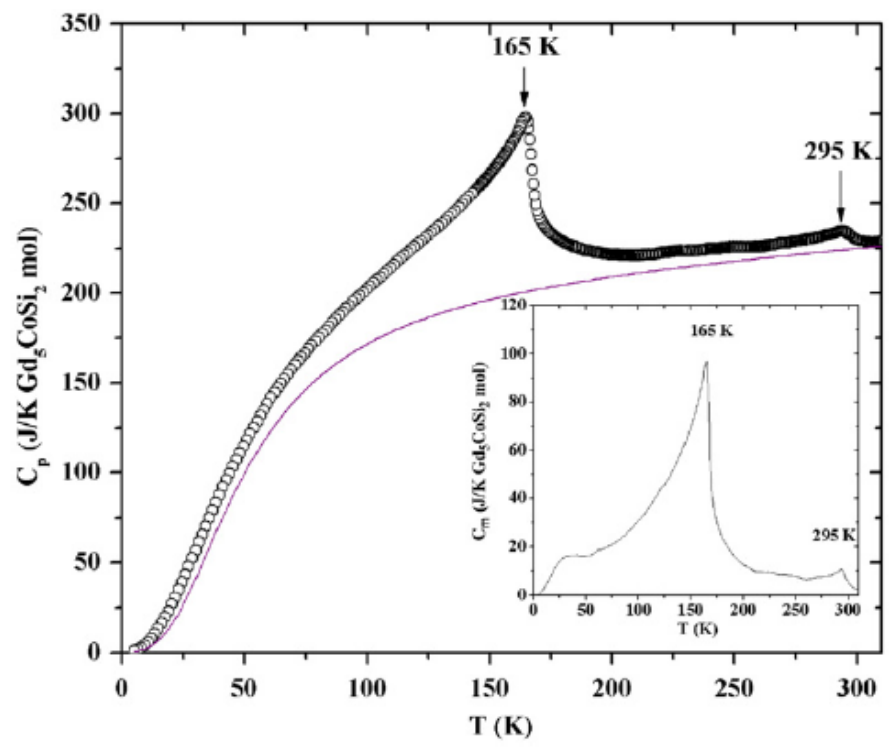

Fig. 6. Temperature dependence of the heat capacity $C_{p}$ of $\mathrm{Gd}_{5} \mathrm{CoSi}_{2}$ (annealed sample) between 5 and $310 \mathrm{~K}$. The line represents the sum of the electronic $\left(\gamma=100 \mathrm{~mJ} \mathrm{~mol}^{-1} \mathrm{~K}^{-2}\right)$ and lattice $\left(\theta_{D}=210 \mathrm{~K}\right)$ contributions. Inset shows the temperature dependence of the magnetic contribution $C_{m}$.

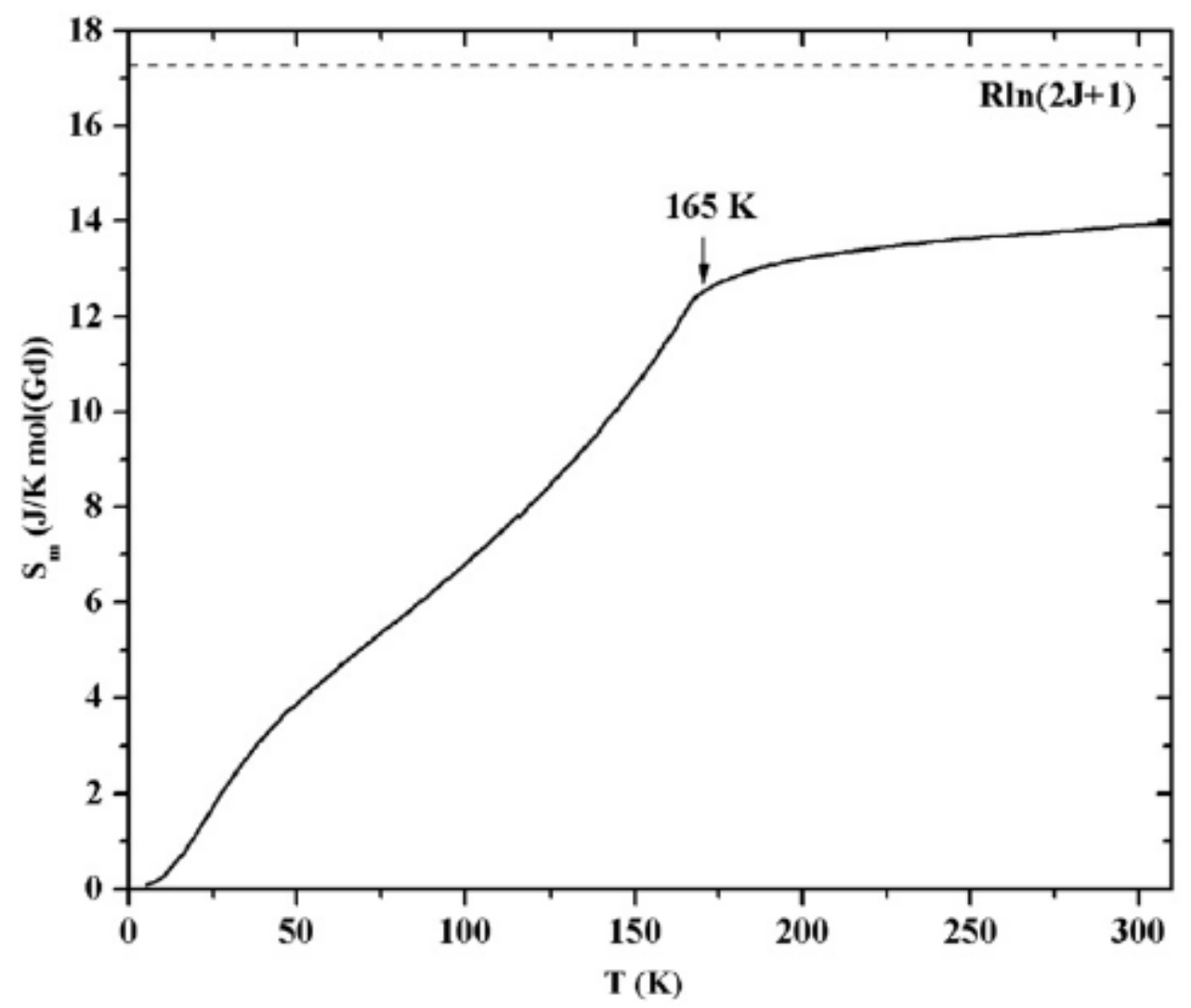

Fig. 7. Temper ature dependence of the magnetic entropy $S_{m}$ of $\mathrm{Gd}_{5} \mathrm{CoSi}_{2}$ (annealed sample). The dashed line represents the theoretical limit $\mathrm{R} \ln (2 J+1)$ with $J=7 / 2$ for $\mathrm{Gd}^{3+}$ ions. 


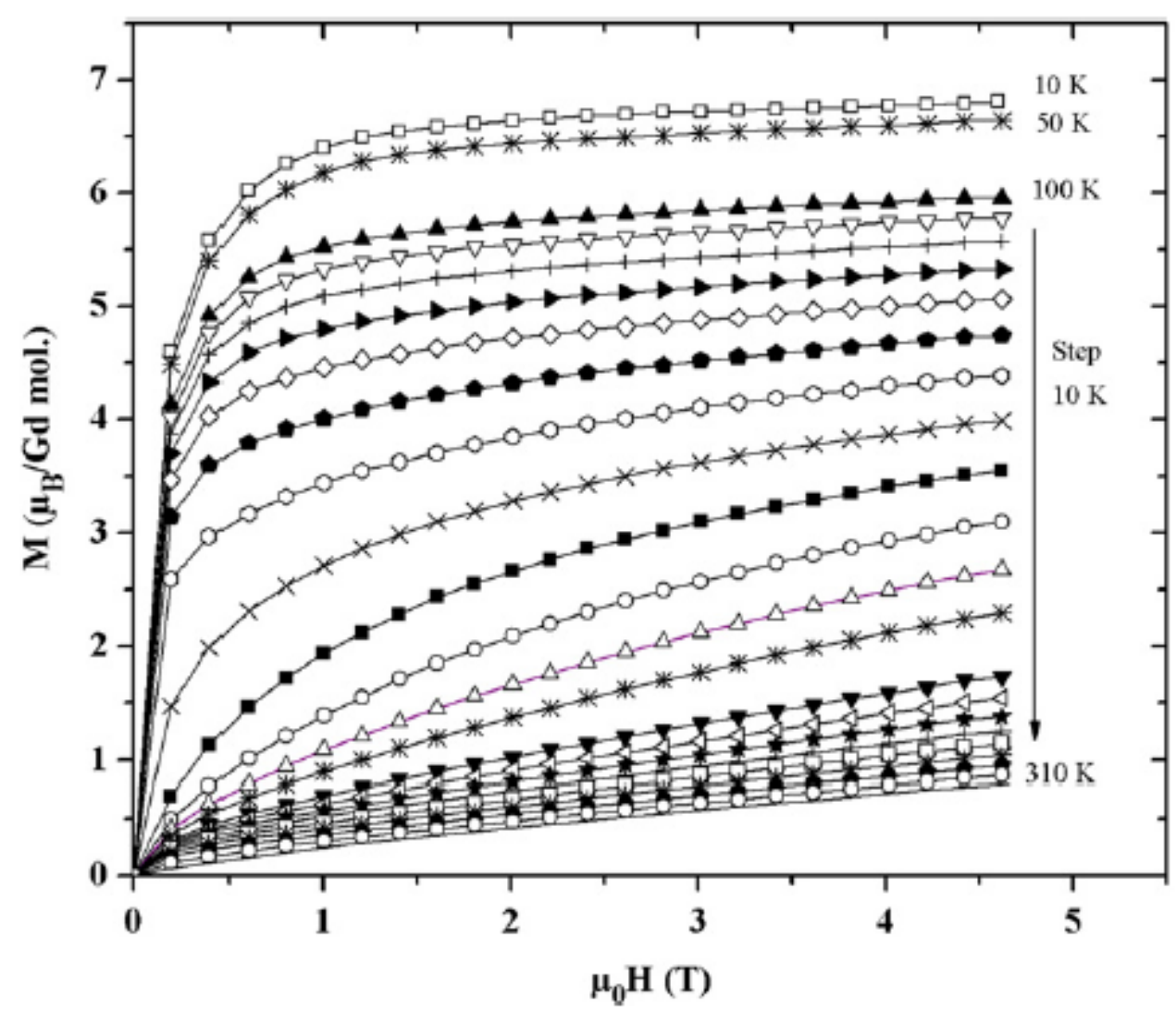

Fig. 8. Field dependence of the magnetization $M$ of $\mathrm{Gd}_{5} \mathrm{CoSi}_{2}$ (annealed sample) measured at various temperatures. 


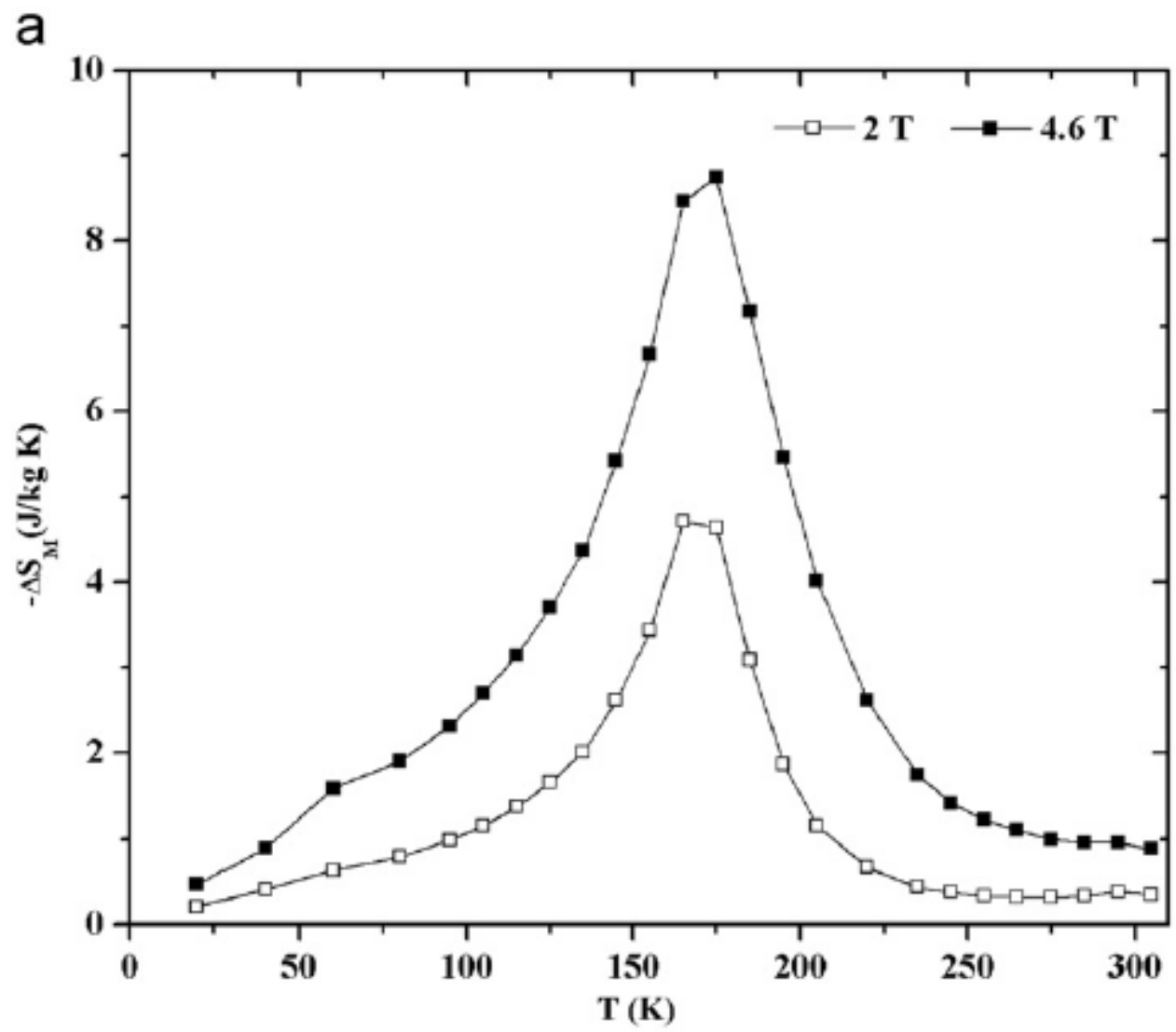

b

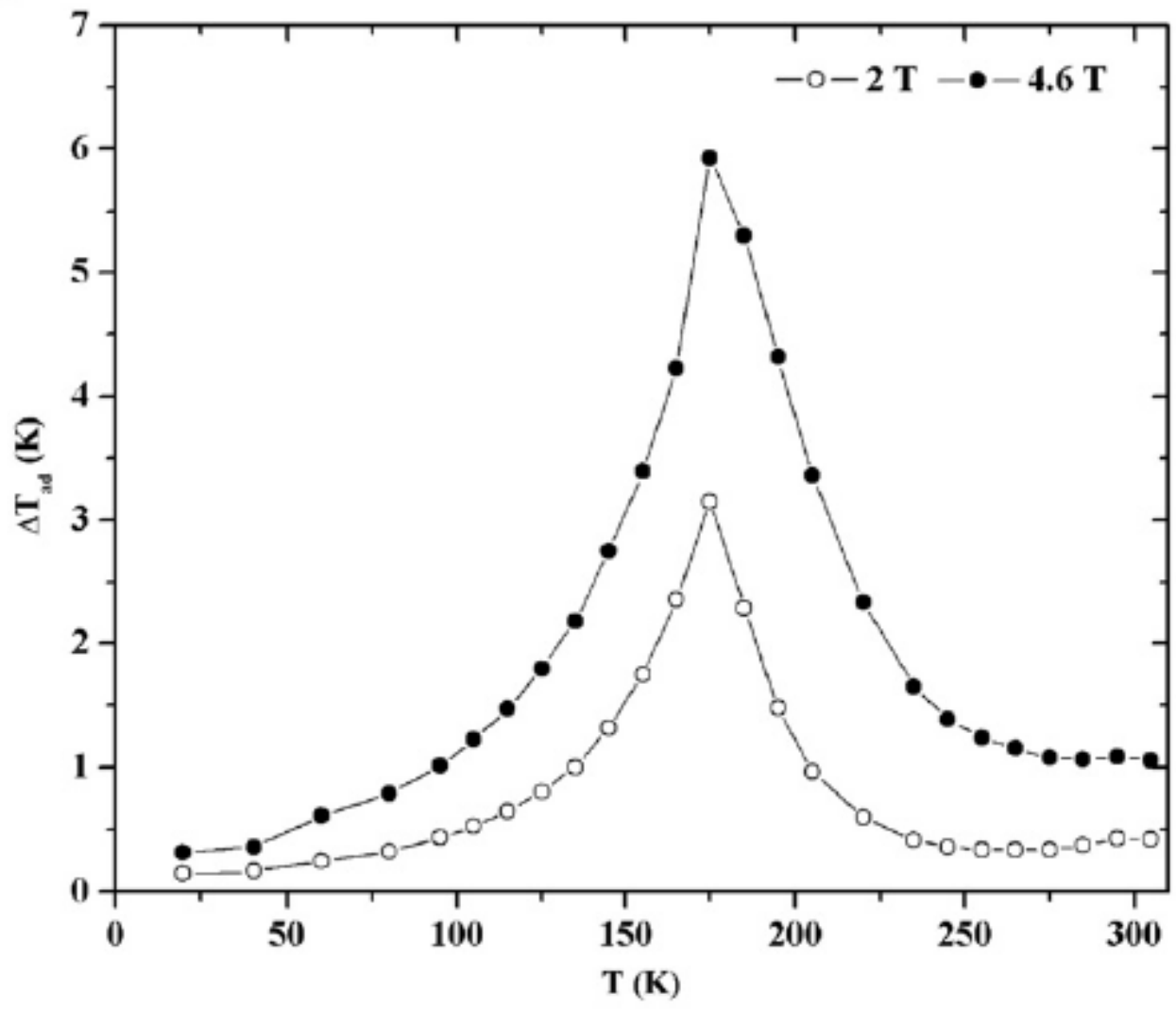

Fig. 9. Temperature dependence of (a) the isothermal magnetic entropy change $\Delta S_{m}$ and (b) the adiabatic temper ature change $\Delta T_{a d}$ for $\mathrm{Gd}_{5} \mathrm{CoSi}_{2}$ (annealed sample) at 2 and $4.6 \mathrm{~T}$. 
Table 1

Atomic coordinates and isotropic displacement parameters $\left(\dot{A}^{2}\right)$ for $\mathrm{Gd}_{5} \mathrm{CoSi}_{2}{ }^{\mathrm{a}}$.

\begin{tabular}{lllllll}
\hline Atom & Site & Occup. & $x$ & $y$ & $z$ & $U_{\text {iso }}\left(\dot{A}^{2}\right)$ \\
\hline Gd1 & $4 c$ & 1 & 0 & 0 & 0 & $0.014(6)$ \\
Gd2 & $16 l$ & 1 & $0.1683(5)$ & $x+1 / 2$ & $0.1438(4)$ & $0.006(4)$ \\
Si & $8 h$ & $1 / 2$ & $0.383(2)$ & $x+1 / 2$ & 0 & $0.010(8)^{\mathrm{b}}$ \\
Co & $8 h$ & $1 / 2$ & $0.383(2)$ & $x+1 / 2$ & 0 & $0.010(8)^{\mathrm{b}}$ \\
Si2 & $4 a$ & 1 & 0 & 0 & $1 / 4$ & $0.010(8)^{\mathrm{b}}$ \\
\hline
\end{tabular}

${ }^{a}$ Space group $14 / \mathrm{mcm}, a=7.5799(4)$ and $c=13.5091(12) \AA$

${ }^{b}$ Constrained to be equal.

Table 2

Number of neighbours and interatomic distances $(\AA)$ in $\mathrm{Gd}_{5} \mathrm{CoSi}_{2}$.

\begin{tabular}{llr}
\hline Gd1: & $4 \mathrm{Si} 1 / \mathrm{Co}$ & $3.036(15)$ \\
& $2 \mathrm{Si} 2$ & $3.3773(6)$ \\
& $8 \mathrm{Gd} 2$ & $3.424(5)$ \\
$\mathrm{Gd} 2:$ & $2 \mathrm{Si} 1 / \mathrm{Co}$ & $2.933(13)$ \\
& $1 \mathrm{Si} 1 / \mathrm{Co}$ & $3.012(13)$ \\
& $2 \mathrm{Si} 2$ & $3.163(5)$ \\
& $1 \mathrm{Gd} 2$ & $3.362(9)$ \\
& $2 \mathrm{Gd} 1$ & $3.424(5)$ \\
& $1 \mathrm{Gd} 2$ & $3.608(5)$ \\
& $2 \mathrm{Gd} 2$ & $3.840(8)$ \\
& $1 \mathrm{Gd} 2$ & $3.885(10)$ \\
& $4 \mathrm{Gd} 2$ & $3.987(5)$ \\
$\mathrm{Si} 1 / \mathrm{Co}:$ & $2.51(2)$ \\
& $1 \mathrm{Si} 1 / \mathrm{Co}$ & $2.933(13)$ \\
& $4 \mathrm{Gd} 2$ & $3.012(13)$ \\
$\mathrm{Si} 2:$ & $2 \mathrm{Gd} 2$ & $3.036(15)$ \\
& $2 \mathrm{Gd} 1$ & $3.163(5)$ \\
& $8 \mathrm{Gd} 2$ & $3.3773(6)$ \\
\hline
\end{tabular}


Table 3

Curie $\left(T_{C}\right)$ or Néel $\left(T_{N}\right)$ temperatures and maximum isothermal magnetic entropy change $\Delta S_{m}^{\max }$ reported in the literature for compounds in the system Gd-Co and for $\mathrm{Gd}_{6} \mathrm{Co}_{1,67} \mathrm{Si}_{3} . \Delta S_{m / G d}^{\max }$ is the maximum isothermal magnetic entropy per weight amount of gadolinium in the sample.

\begin{tabular}{|c|c|c|c|c|c|}
\hline & & $\begin{array}{l}\Delta S_{m}^{\max } \\
\left(\mathrm{J} \mathrm{kg}^{-1} \mathrm{~K}^{-1}\right)\end{array}$ & $\begin{array}{l}\Delta S_{m / G d}^{\max } \\
\left(\mathrm{J} \mathrm{kg}_{(\mathrm{Gd})}^{-1} \mathrm{~K}^{-1}\right)\end{array}$ & $\begin{array}{l}\Delta H \\
(\mathrm{~T})\end{array}$ & Reference \\
\hline $\mathrm{Gd}_{5} \mathrm{CoSi}_{2}$ & $T_{C}=168 \mathrm{~K}$ & $\begin{array}{l}-4.7 \\
-8.7\end{array}$ & $\begin{array}{l}-5.4 \\
-10.0\end{array}$ & $\begin{array}{l}2 \\
4.6\end{array}$ & This work \\
\hline $\mathrm{Gd}_{6} \mathrm{Co}_{1.67} \mathrm{Si}_{3}$ & $T_{C}=294 \mathrm{~K}$ & $\begin{array}{l}-2.9 \\
-5.7\end{array}$ & $\begin{array}{l}-3.5 \\
-6.8\end{array}$ & $\begin{array}{l}2 \\
4.8\end{array}$ & [6] \\
\hline Gd & $T_{C}=294 \mathrm{~K}$ & $\begin{array}{l}-5.5 \\
-10.3\end{array}$ & $\begin{array}{l}-5.5 \\
-10.3\end{array}$ & $\begin{array}{l}2 \\
5\end{array}$ & [1] \\
\hline $\mathrm{Gd}_{12} \mathrm{Co}_{7}$ & $T_{C}=163 \mathrm{~K}$ & -4.6 & -5.6 & 2 & [37] \\
\hline $\mathrm{Gd}_{3} \mathrm{Co}_{0}$ & $T_{N}=128 \mathrm{~K}$ & -11.0 & -12.4 & 5 & [38] \\
\hline $\mathrm{Gd}_{4} \mathrm{CO}_{3}$ & $T_{C}=220 \mathrm{~K}$ & $\begin{array}{l}-2.7 \\
-5.7\end{array}$ & $\begin{array}{l}-3.5 \\
-7.3\end{array}$ & $\begin{array}{l}2 \\
5\end{array}$ & [39] \\
\hline $\mathrm{Gd}_{6} \mathrm{Co}_{4.85}$ & $T_{C}=219 \mathrm{~K}$ & $\begin{array}{l}-2.4 \\
-4.8\end{array}$ & $\begin{array}{l}-3.1 \\
-6.3\end{array}$ & $\begin{array}{l}2 \\
4.5\end{array}$ & [10] \\
\hline
\end{tabular}

